\title{
A Study on the Effects of the Jeong-Jwa Activity Based on Toegye Yi Hwang's Idea of Gyeong on Korean High School Students' Creative Personality
}

\author{
Seak-Zoon Roh ${ }^{1}$, YongNam Yun ${ }^{2 *}$ and Jin Sung Yang ${ }^{3}$ \\ ${ }^{1}$ Sungshin Women's University \\ ${ }^{2}$ Sungshin Women's University \\ ${ }^{3}$ Young Shin Girl's High School \\ ${ }^{1}$ szroh@sungshin.ac.kr, ${ }^{2}$ yyoon sungshin.ac.kr, ${ }^{3}$ jins5480@ @daum.net
}

\begin{abstract}
The purpose of this study was to conduct an experiment on the students attending an academic high school by setting a Jeong-jwa activity as part of regular classes, and to investigate the changes in creative personality. Jeong-jwa is one of the practices of Toegye Yi Hwang's idea of Gyeong. One hundred and fifty five (155) high school students were gathered and divided into two groups (experimental group: 2 classes, 59 students, 38.1\%; control group: 3 classes, 96 students, 61.9\%). A creative personality test developed by the Korean Educational Development Institute (KEDI) in 2011 was utilized for measuring the students' level of creative personality. The test consisted of 6 subfactors (curiosity, task commitment, aesthetics, risk taking, open-mindedness, and independence of judgment) with a total of 27 items rated on a 4-point Likert scale. The pretest and posttest were analyzed with One-way ANCOVA, except for 'open-mindedness' and 'independence of judgment' among sub-factors because of lower reliability. The results showed that the main effect on creative personality and task commitment, aesthetics, and risk taking among the sub-factors of creative personality had statistically significant differences between the two groups. Nevertheless, the main effect on curiosity had no statistically significant difference between the two groups.
\end{abstract}

Keywords: Gyeong, Toegye Yi Hwang, Jeong-jwa, Creative Personality, Korean High School Students

\section{Introduction}

To educate future generations well, the learning content and methods applied need to be appropriate for the society of the future. This means that the learning content and methods in school education need to include a wide variety of knowledge, capabilities, values, and attitudes required by the future society in which today's young people will live [1]. It is impossible to cover the overflowing amount of knowledge and information in the world today in school education while encouraging the students to accept the learning content.

To prepare future generations to adapt well to the 21st century, which is growing in complexity due to the rapid expansion of the types and ranges of knowledge, schools need to teach students the ability to proficiently process this expanding information and knowledge, and to efficiently manage the knowledge that they have. In addition, students should be able to select from the various knowledge and information available, and focus on the learning content that they need. To use a common phrase, a strategy of 'selection and concentration,' which is well known in our society, is what today's learners need.

*Corresponding Author 
Therefore, learners must develop the ability to select and sort out key concepts by actively involving themselves as the main agents in the learning process, and to solve the problems by focusing on and challenging the new learning process by themselves. Such capabilities have been discussed as key elements of the 'creative personality.'

On the other hand, the characteristics of the creative personality can be identified as curiosity, task commitment, independence of judgement, risk taking, open-mindedness, aesthetics and attraction to complexity. Song and Kim [2] extracted the factors of curiosity, variety of interest, immersion in things of interest, individuality, peculiar preference, denormalization and openness as the affective characteristics of creative persons.

Ha [3-4] also pointed out curiosity, self-assurance, imagination, patience/obsession, humor, independence, adventure, and openness as the characteristics of a creative personality in studies on the creative personality. In addition, it was found that creative personalities had a high correlation between the self-selection of behavior's motive, essential interest in learning activity and a positive attitude toward learning [5- 6]. From this perspective, this study aimed to focus on the study of 'Gyeong (敬)' as discussed in Confucianism.

Gyeong (敬, reverent seriousness) has been discussed as a study method in the traditional sense, which is for moral training. Since Gyeong was used in various contexts, not all of them can be listed; and yet Gyeong can be understood as concentrating on the object in order to value it and treat it carefully whether it is a person or a task, and as coming to one's senses at all times in order to concentrate. When the task at hand is an academic activity, Gyeong is an important attitude for learners to possess. 'Coming to one's senses' and 'concentration' are both crucial elements necessary for learners to control and focus on their learning process.

Meanwhile, creative personality, characterized by such hallmarks as curiosity, task commitment, aesthetics, risk taking, and open-mindedness, is emphasized as one of the important competencies of learners in the 21 st century. Therefore, it is necessary to establish and implement specific teaching-learning methods to nurture such competency through a school learning process.

This study conducted an experiment on students attending an academic high school by setting a Jeong-jwa (靜坐, jìng-zuò; quiet-sitting) activity, which is one of the practices of Toegye Yi Hwang's idea of Gyeong, as part of regular classes, and examined the changes in creative personality between the experimental group and the control group.

\section{Literature Review}

According to the analysis on the examples of Gyeong (敬) used in the Four Books of Ancient China (四書, the Analects of Confucius, the Works of Mencius, the Doctrine of the Mean and the Great Learning) or the Five Classics of Confucianism (五經, the Classic of Poetry (Shih Ching), the Book of Documents (Shujing), the Book of Changes(I ching), the Classic of Rites (Liji), and the Spring and Autumn Annals (Chunqiu)), Gyeong can be divided according to themes related to honor, respect, prudence, and caution. Since respect can be included in honor and caution can be included in prudence, Gyeong can for the most part be categorized based on honor and prudence. The ancient Confucians interpreted Gyeong (敬) as honor, which is treating people or objects in a precious and careful manner. Therefore, honor and prudence can be understood as having similar meanings [7].

Although Gyeong (敬) has been valued from the period before the Qin Dynasty of China, and the neo-Confucianism in the Song Dynasty of China, in particular, Cheng Yi (1033 1107), a Chinese philosopher, understood Gyeong as a unique psychological state and also as the method to reach to this psychological state. Against this backdrop, Chu 
Hsi (朱子) expanded the meaning of Gyeong (敬) by connecting it to the Theory of Mind-Body Relation (理氣心性論) [8]. Chu Hsi (朱子) started to pay attention to Gyeong (敬) as those characteristics of studying that spring from the need for a method of study that goes beyond the boundaries of weifa (未發, the state before being aroused) and ifa (已發, the state after being aroused) of the mind (心) during the process of discussing ways to develop and introspect in the state of weifa (未發) and ifa (已發) that originated from 'The Mean (中庸)'. Under the influence of Chu Hsi (朱子) during the latter period, weifa (未發) and ifa (已發) were not clearly divided. Therefore, this should naturally lead to the study of weifa (未發) and ifa (已發), which are considered to be possible with Gyeong (敬). If a person adopts the attitude of Gyeong (敬), this naturally leads to the study of Cunyang (存養) in the state of weifa (未發) of the mind (preserving mind and maintaining a good disposition) and the study of introspection was conducted in the state of ifa (已發). Only then, the original state of mind - jung hwa (中和, jung (中) refers to the state where emotions are not expressed yet and hwa (和) refers to the state where emotions are consistent with what is right) -, in other words, original mind (本心) can be maintained.

For Chu Hsi, Gyeong (敬) allows the original mind (本心) to be maintained during all studies and in the course of life, which is because Gyeong (敬) presides over mind.

Gyeong (敬) is the fundamental basis of everything as a presider of mind.

(Questions and Answers concerning The Great Learning (大學或問), General theory) Gyeong (敬) is where mind (心) presides over itself.

\section{(Classified Conversations of Master Chu (朱子語類) 12-92)}

This way, the grounds for presiding over mind is Gyeong (敬). Gyeong (敬) is not presiding over mind because it is out of mind, but it is Gyeong which is used when the mind presides over itself. By presiding over mind and maintaining the original mind through Gyeong (敬), the foundation is established to understand and handle the reasons and causes of everything in the world.

The original mind is the main agent that can respond to everything in the world, as it has all reasons in it because it is empty and bright (虛明). If it is possible to maintain the brightness of the original mind with the attribute to preside over mind through Gyeong (敬), the principle (li, 理) can be clear regardless of the states of weifa (未發) and ifa (已發) of the mind. In this regard, Chu Hsi said “since Gyeong (敬) is the mind in a state of always being awake so that it is mostly bright and not dark, the heaven's principle (tianli, 天理) flows forth at any time. This is mainly the grounds for the study of Gyeong (敬) [9].” Chu Hsi also mentioned that, “if a human can maintain Gyeong, his/her mind becomes clear and the heaven's principle becomes illuminating [10].” Or, “Gyeong (敬) makes the heaven's principle bright and naturally suppresses and eliminates human greed (人欲) [11].” This way, maintaining the attribute of presiding over mind and original mind (本心) through the study of Gyeong (敬) is not separated from identifying the heaven's principle (天理). If it is not possible to reflect on the principle ( $l i$, 理) of mind and all things with the original mind, even though the original mind was identified, it is not a proper study of Gyeong (敬).

After all, the study of Gyeong (敬) can be regarded as an effort to preside over ourselves and not to be swayed by the external environment or organic restrictions, as our mind is always awake in every situation of life. The awake mind refers to always recovering consciousness and not being swayed by external or internal restrictions and can be regarded as concentrating mind in order not to escape from the principle ( $l i$, 理) associated with taking action. 
In other words, Gyeong (敬) wakes up the spirit of the mind to concentrate our mind on the tasks we want to do now. However, if there are some tasks to do, there are some things to focus on but if there are no tasks to do, there is nothing to focus on. Therefore, 'coming to one's senses' includes the state when there are no tasks to be performed. Therefore, Gyeong (敬) is 'coming to one's senses' and can be summarized as 'concentration'. 'Coming to one's senses' is the original substance (本體) that includes when there are no tasks and when there are tasks, or in other words, activity and stillness (動·靜), and 'concentration' is when there are tasks, or in other words, practicing (活用) in the activity [7].

Toegye basically followed the teaching methods of Cheng Zi (程子), Xie Shang-Cai (謝上蔡) and Yin he jing (尹和靖) as summarized by Chu Hsi regarding the methodological characteristics of the study of Gyeong, in other words, 'staying focused by forgetting distractions (主一無適)', 'properly ordered and controlled, grave and quiet (整齊嚴肃)', 'always staying awake by not being careless (常惺惺)', and 'staying focused without embracing other thoughts (心收斂不容一物)'. However, Toegye did not just introduce these methods in a two-dimensional way; he also acquired these methods in his own way and reached the status of Gyeong (敬) at the highest level through the 'Toegye style' theory of the study of Gyeong (敬). The ideologies and studies of all explanatory diagrams of Sung Hak Sip Do (the Ten Diagrams of Sage Learning, 聖學十圖) by Toegye carry out Gyeong (敬).

According to Toegye, no part of daily life can be excluded from the study of Gyeong (敬). All temporal and spatial situations become opportunities of study, and study should be done in any temporal and spatial situation. One of the convincing reasons that Toegye proposes for considering daily life as a place of study is that daily life is where dao (道) is practiced. Since dao (道) exists in any time and space of daily life, the study to realize dao (道) can be and should be conducted using all time and space. No matter how secret and individual the time and space are, there should be an effort to continue to correspond to dao (道).

In this sense, Toegye puts great emphasis on the study of Gyeong as being a study that moves between the activity and stillness (動.靜) of mind. In other words, the study of Gyeong (敬) is a study of “moral cultivation and self-reflection (存養省察, 存養 (jonyang): preserving mind and maintaining a good disposition, 省察 (seongchal): checking after self-reflection) depending on the place and time by the stillness and the activity". One of the points emphasized by Toegye in "Sung Hak Sip Do (the Ten Diagrams of Sage Learning)', along with Maxims of the Reverence Studio (Jingzhai zhen, 敬齋箴)' and Admonition on Rising Early and Retiring Late (Sukheung yamaejam, 咸興夜宊筬)', was that Gyeong (敬) is a study that moves between the activity and stillness (動·靜) of mind. However, Toegye emphasized the study of the stillness by identifying the stillness as being more fundamental than the activity of mind. Mind can strengthen the foundation to reveal the fundamental aspects of people through the study that reaches the state of weifa (未發), in other words, the stillness. Mind can reveal and reflect the principle ( $l i$, 理) in an easier and more natural way in the activity (動) only if it is firmly rooted in the foothold of the stillness that perceives the intuition of mind itself. In this way, Toegye values the stillness as being more fundamental but at the same time remains vigilant against the Buddhist tendency to favor the stillness. Using Gyeong (敬) rather than the stillness is not to overlook preparing for the activity (動) based on the stillness (靜) [12].

The significance of Gyeong lies in its aim of fashioning a human person that always concentrates on all kinds of problems in life with a serious and calm attitude. 
Toegye stated that Gyeong is always required whether it is weifa (the state before being aroused) or ifa (the state after being aroused), or whether there is something to do or not [13]. Gyeong draws the study on weifa to the study on ifa, or vice versa. Toegye demanded jusa, which is the convergence of body in ifa, more than anything from beginners, but what he truly emphasized was jujeong (mainly staying in the stillness), which is concentration of mind in weifa. Toegye emphasized the importance of bodily convergence because it was ultimately his way to concentrate his mind. The external features of convergence such as adjusting the collar, taking heavy footsteps, or making polite hand gestures were all preparations for concentration of the mind.

What Toegye valued as a way to achieve a pious attitude was 'Jeong-jwa'. Toegye recommends Jeong-jwa as a specific way of implementing Gyeong that presides over the mind. He believed that the body and mind are collected and gathered together in one place only after Jeong-jwa. Thus, if the body is thoughtlessly left in a state of disorder, the body and soul will be in confusion, and focus on righteous duty cannot be achieved [14].

It is hard to know accurately the period when Jeong-jwa started to be accepted. However, it may have taken hold from the time when Chou Lien-hsi outlined 'Jujeongibingeuk (主靜立人極, setting the standard behavior of humans mainly based on the stillness)' in his Taijitushuo (太極圖說), Jeong Myeong-do (程明道) and Jeong Icheon (程伊川) taught Jeong-jwa and Lee Yeong-pyeong (李 延平) emphasized Mukjwajingsim (黑坐澄心, sitting quietly and clearing the mind). In addition, Chu Hsi emphasized jujeong (主靜, mainly staying in the stillness) as the best training method rather than jugyeong (主敬, mainly practicing Gyeong) but often valued Jeong-jwa by arguing for 'sitting in the Jeong-jwa position for half the day and reading books for half the day (牛日靜坐, 牛日讀書). In this way, Jeongjwa was used as a study method when handling tasks or before encountering objects often when sitting still by being accepted by Confucianism after the neoConfucianism of the Song Dynasty.

Although Jeong-jwa is necessary for the study of Gyoeng (敬), Chu Hsi mentioned that it is not the same Jeong-jwa activity that stops consideration based on Jwaseonipjeong (坐禪入定, reaching dhyāna (禪定, quiet contemplation) through Zen meditation (參禪)). Jeong-jwa means collecting the mind and consideration does not mean wandering freely [15]. Therefore, "Gyeong does not mean sitting upright alone and avoiding things that cannot be heard by ears, seen by the eyes and thought by the mind. Gyeong means to be wary and careful of things and avoiding self-indulgence [15]." Therefore, Jeong-jwa of Chu Hsi should be distinguished from the jwa-seon (sitting in Zen meditation) of Buddhism, and the study of Gyeong (敬) of Chu Hsi is the study that should be conducted at the level of daily life.

Since the study of 'preserving mind (cun xin 存心)' and 'nourishing the moral nature (yang xin 養性, the original form of Cunyang (存養)) is not performed only in the Jeongjwa activity, it will not be stopped only if the study should be continued in any places during our daily life.

(The Collected Works of Chu Hsi (朱喜集), vol. 56).

The so-called study of preserving mind (存心) by Chu Hsi does not mean sitting quietly and closing one's eyes like a straw man. If you respond to the tasks (事) and do not lose mind when encountering objects (物), that is the study of cultivation of mind. It is necessary to read the intention of Chu Hsi, under which he used Gyeong (敬) instead of the stillness (靜), in the same context. Therefore, it is noticeable that the study of 'preserving mind (cun xin 存心)' and 'nourishing the moral nature 
(yang xin 養性)' is regarded as being always awake during daily life. The study of Gyeong (敬) of Chu Hsi is nothing more than collecting words and behaviors from daily life. Also, the study of Gyeong (敬) is not seriously solidified and is not like the study of Buddhism.

Toegye focuses on Jeong-jwa that calms the mind down. In the study of Gyeong, substantial and constant practice is more important than a few theoretical statements or pieces of knowledge. Toegye's life involved consistent practice of Gyeong from getting up in the morning to falling asleep at night, with convergence of being properly ordered and controlled on the inside by adjusting the outward appearance, study of how to be grave and quiet, cultivation of the mind and introspection of the interior life through Jeong-jwa, and reading based on the above.

He woke up early in the morning, washed his face, combed his hair, put on a crown, got dressed, read books all day long, and would reflect calmly in a quiet, sitting position (Jeong-Jwa, 靜坐) with incense burning, sometimes until the sun rose.

(Master Toegye Chronicle of One's Sayings and Doings, vol. 1, p. 14)

He maintained a quiet sitting position (靜坐) and sometimes sat in a lotus position (盤 坐) but never tilted or leaned his body on something. He only closed his eyes and sat squarely when he was tired.

(Master Toegye Chronicle of One's Sayings and Doings, vol. 2, p. 75)

The life of Toegye was the practice of Gyeong (敬) maintained from waking up to sleep in a combined form of the study of properly ordered and controlled, grave and quiet (整齊嚴肅) that corrects the externality (外形) and disciplines the inner side, the study of inner development and introspection through a Jeong-jwa activity and the study of reading based on the above studies.

'Doin Gigong technique', which is known as a daily exercise of Toegye, takes the traditional form of Eastern Gigong technique. Eastern Gigong is characterized by its emphasis more on the inner world than outer movements. As it originates from gèn guà (艮卦, Hexagram 52 of I Ching) [16], the Eastern discipline of meditation focuses on being calmly seated, discontinuing emotions toward external objects, and emptying the mind. 'Doin Gigong technique' begins from feeling vitality from deep inside the mind by 'calming the mind down'. And it ends by 'closing the eyes and quietly waiting for the vitality that slowly surges from the center of the abdomen'. However, the stage that Toegye aims to reach through Jeong-jwa is quite different from that of Buddhism.

Toegye said 'Gyeong' is the beginning and end of seonghak (sage learning). Gyeong is the first principle of a discipline to cultivate the moral foundation of character on the inside and controlling the kind of behavior that reveals evil on the outside. The study of mind to follow and practice the order of heaven in the human mind according to the principle of Gyeong is the starting point as well as the goal of moral philosophy for Toegye [17].

Through Gyeong, Toegye emphasized that the mind in quietly sitting down and being engaged in an activity becomes consistent, and that consistent behavior on the inside and the outside must become a habit. Once someone embodies the study of Gyeong, he can naturally develop behavioral patterns to suitably deal with events and objects that are encountered on the inside and the outside. To this end, it is necessary to constantly pay attention to the mind and be aware of the signs that signify wriggling deep inside the mind. The fact that Toegye valued 'Hwal-in-simbang' and practiced it every day is also closely related to his method of study focused on Gyeong. 


\section{Methods}

\subsection{Participants}

This study focused on 155 students in 5 freshman classes in Y Girls' High School in Gyeonggi-do. To verify the effects of Jeong-jwa on the creative personality of the high school students, this study divided the students taking the ethics class into an experimental group ( 2 classes, 59 students, 38.1\%) and control group (3 classes, 96 students, $61.9 \%$ ) for comparative analysis.

The experimental group that participated in class that included the Jeong-jwa activity was told to participate in the Jeong-jwa activity for 5 minutes at the beginning of the ethics class that takes up an hour every week for 8 weeks, and then the rest of the class took place in the manner it was normally conducted in.

The control group participated in the usual class, adopting the current teaching method without such Jeong-jwa activity. After the 8-week experiment, the testing tool similar to the one used for pre-testing purposes was used for post-testing the high school students in the experimental group and control group.

\subsection{Instruments}

To measure the level of creative personality of the students, this study used the creative personality test for secondary school developed by the Korean Educational Development Institute (KEDI) in 2011. This is a test for middle and high school students consisting of 6 sub-factors (curiosity, task commitment, aesthetics, risk taking, open-mindedness, and independence of judgment) with a total of 27 items rated on a 4-point Likert scale. The reliability (Cronbach's a) of the creative personality test in this study was .85 in the pretest and .86 in the posttest.

\subsection{Instruments}

The purpose of this study was to compare and analyze the differences in creative personality between the group that set a Jeong-jwa activity and the group that did not set the activity during the ethics class of the first year students in $\mathrm{Y}$ girl's high school in Gyeonggi Province. To this end, this research used one of the methods of 'quasi-experimental design,' which was 'nonequivalent control group pretestposttest design.'

\begin{tabular}{|c|c|c|}
\hline$O_{1}$ & $X$ & $\mathrm{O}_{2}$ \\
\hline & & $\mathrm{O}_{4}$ \\
\hline
\end{tabular}

Note 1: $\mathrm{O}_{1}$ : pretest of experimental group, $\mathrm{O}_{2}$ : posttest of experimental group, $\mathrm{O}_{3}$ : pretest of control group, $\mathrm{O}_{4}$ : posttest of control group, $X$ : experimental treatment Note 2: The dotted line in this figure means that the two groups are not homogenized.

\section{Figure 1. Research Design Model (Nonequivalent Control Group Pretest- Posttest Design)}

\subsection{Analysis}

Reliability of the pretest and posttest for 'open-mindedness' and 'independence of judgment' among sub-factors was lower than .60, and thus the two factors were excluded from analysis. The data collected through the pretest and posttest were analyzed with One-way ANCOVA using the SPSS 22.0 Windows program. The significance level set in this study was $p<.05$. 


\section{Results}

To examine the effects of class activities including Jeong-jwa on the creative personality of the high school students, the pretest and posttest results of the experimental and control group were analyzed for each group.

Table 1. Analysis of Group Differences on Creative Personality

\begin{tabular}{|l|c|c|c|c|}
\hline \multirow{2}{*}{\multicolumn{1}{|c|}{ Group (N) }} & \multicolumn{2}{|c|}{ Pretest Score } & \multicolumn{2}{c|}{ Adjusted Posttest Score } \\
\cline { 2 - 5 } & \multicolumn{2}{|c|}{$M$} & SD & \multicolumn{2}{c|}{ SD } \\
\hline Experiment (72) & 3.42 & .43 & 3.56 & .41 \\
\hline Control (69) & 3.38 & .43 & 3.40 & .43 \\
\hline
\end{tabular}

Looking at the average score of the pretest and posttest of creative personality by group, the gap in the pretest score between the control group $(M=3.38, S D=.43)$ and the experimental group $(M=3.42, S D=.43)$ was .04 , while the difference in the adjusted posttest score with the pretest score as a covariate between the control group $(M=3.40, S D=.43)$ and the experimental group $(M=3.56, S D=.41)$ was .16 .

To determine whether there was a difference in the creative personality scores between the two groups depending on the application of class activities including Jeong-jwa, the pretest score was set as covariate and the posttest score was set as the dependent variable for analysis of covariance (See Table 2).

The results showed that the main effect on creative personality was $F=9.06$ ( $p<$ $.01)$; thus, there was a statistically significant difference between the two groups with the pretest score controlled. Therefore, in general, it can be seen that the Jeongjwa activity is effective in promoting the creative personality of the high school students.

Table 2. Covariate Analysis on Creative Personality by Group

\begin{tabular}{|l|r|r|r|r|}
\hline \multicolumn{1}{|c|}{ Source } & \multicolumn{1}{|c|}{ SS } & \multicolumn{1}{|c|}{ df } & \multicolumn{1}{c|}{ MS } & \multicolumn{1}{|c|}{} \\
\hline Corrected Model & 17.68 & 1 & 17.68 & $268.20^{* * *}$ \\
Intercept & .59 & 1 & .59 & $9.06^{* *}$ \\
Error & 10.02 & 152 & .06 & \\
Total & 28.63 & 154 & & \\
\hline
\end{tabular}

$p<.01,{ }^{* * * *} p<.001$

Meanwhile, the research compared the average and standard deviation values of the pretest and posttest by group for the sub-factors of creative personality of curiosity, task commitment, aesthetics, risk taking, open-mindedness and independence of judgement to specifically identify which sub-factors of creative personality were improved by the class activities, including the Jeong-jwa activity. The results are shown in Table 3.

Table 3. Mean and Standard Deviation on the Sub-factors of Creative Personality by Group

\begin{tabular}{|l|l|c|c|c|c|}
\hline \multirow{2}{*}{} & \multirow{2}{*}{ Group (N) } & \multicolumn{2}{|c|}{ Pretest Score } & \multicolumn{2}{c|}{$\begin{array}{c}\text { Adjusted Posttest } \\
\text { Score }\end{array}$} \\
\cline { 3 - 6 } & & $M$ & SD & $M$ & SD \\
\hline Curiosity & Experiment (72) & 3.62 & .69 & 3.86 & .54 \\
\cline { 2 - 6 } & Control (69) & 3.45 & .67 & 3.61 & .68 \\
\hline Task Commitment & Experiment (72) & 3.10 & .62 & 3.33 & .57 \\
\hline
\end{tabular}




\begin{tabular}{|l|l|l|l|l|l|}
\hline & Control (69) & 3.16 & .67 & 3.22 & .66 \\
\hline \multirow{2}{*}{ Aesthetics } & Experiment (72) & 3.27 & .94 & 3.44 & .89 \\
\cline { 2 - 6 } & Control (69) & 3.13 & .91 & 3.13 & .88 \\
\hline \multirow{2}{*}{ Risk taking } & Experiment (72) & 3.52 & .62 & 3.73 & .62 \\
\cline { 2 - 6 } & Control (69) & 3.53 & .70 & 3.43 & .75 \\
\hline
\end{tabular}

Table 3 compared the average score of the pretest and posttest between the two groups by the sub-factors of creative personality. The difference between the control group $(M=3.45, S D=.67)$ and the experimental group $(M=3.62, S D=.89)$ in the pretest score of curiosity was .17, while the difference between the control group ( $M$ $=3.61, S D=.68)$ and the experimental group $(M=3.86, S D=.54)$ in the adjusted posttest score with the pretest score as a covariate was .25 .

In terms of task commitment, the difference between the control group $(M=3.16$, $S D=.67)$ and the experimental group $(M=3.10, S D=.62)$ in the pretest score was .06 , while the difference between control group $(M=3.22, S D=.66)$ and the experimental group $(M=3.33, S D=.57)$ in the adjusted posttest score with the pretest score as a covariate was .11. In particular, the control group had a difference of .6 between the posttest and the pretest, while the experimental group had a significantly huge difference of .20.

In terms of aesthetics, the gap between the control group $(M=3.13, S D=.91)$ and the experimental group $(M=3.27, S D=.94)$ in the pretest score was .14 , while the difference between the control group $(M=3.13, S D=.88)$ and the experimental group $(M=3.44, S D=.89)$ in the adjusted posttest score with the pretest score as a covariate was .31. The control group had the same pretest and adjusted posttest scores, while the experimental group had a higher posttest score than the pretest score by .17 .

In terms of risk taking, the difference between the control group $(M=3.53, S D=$ $.70)$ and the experimental group $(M=3.52, S D=.62)$ in the pretest was .01 , while the difference between the control group $(M=3.43, S D=.75)$ and the experimental group $(M=3.73, S D=.62)$ in the adjusted posttest with the pretest score as a covariate was .30. The control group had a posttest score that was lower than the pretest score by .10, while the experimental group had an adjusted posttest score that was higher than the pretest score by .21 .

Meanwhile, to determine whether there was a change in the sub-factor score of creative personality between the two groups with slight differences depending on whether class activities including Jeong-jwa were applied and among sub-factors, the pretest score was set as covariate and the posttest score was set as the dependent variable for analysis of covariance.

Table 4. ANCOVA Results Among Groups on Sub-Factors of Creative Personality

\begin{tabular}{|l|l|r|r|r|r|}
\hline & \multicolumn{1}{|c|}{ Source } & \multicolumn{1}{c|}{ SS } & \multicolumn{1}{c|}{ df } & \multicolumn{1}{c|}{ MS } & \multicolumn{1}{c|}{$F$} \\
\hline Curiosity & Corrected Model & 24.41 & 1 & 24.41 & $99.07^{* * *}$ \\
& Intercept & .88 & 1 & .88 & 3.57 \\
& Error & 37.45 & 152 & .29 & \\
& Total & 58.35 & 154 & & \\
\hline Task Commitment & Corrected Model & 34.69 & 1 & 34.69 & $201.58^{* * *}$ \\
& Intercept & .87 & 1 & .87 & $5.08^{*}$ \\
& Error & 26.16 & 152 & .17 & \\
& Total & 61.30 & 154 & & \\
\hline Aesthetics & Corrected Model & 77.37 & 1 & 77.37 & $271.71^{* * *}$ \\
& Intercept & 1.31 & 1 & 1.31 & $4.61^{*}$ \\
\hline
\end{tabular}




\begin{tabular}{|l|l|r|r|r|r|}
\hline & Error & 43.28 & 152 & .28 & \\
\hline Total & 124.06 & 154 & & \\
& Corrected Model & 24.74 & 1 & 24.74 & $72.02^{* * *}$ \\
& Intercept & 3.45 & 1 & 3.45 & $10.04^{* *}$ \\
& Error & 52.22 & 152 & .34 & \\
\hline${ }^{*} p<.05,{ }^{* *} p<.01,{ }^{* * * *} p<.001$ & 80.30 & 154 & & \\
\hline
\end{tabular}

The results showed that the main effect on task commitment among the subfactors of creative personality was $F=5.08(p<.05)$, the main effect on aesthetics was $F=4.61(p<.05)$, and the main effect on risk taking was $F=10.04(p<.01)$; thus, there was a statistically significant difference between the two groups with the pretest score controlled. Therefore, it can be seen that class activities including Jeong-jwa affect task commitment, aesthetics, and risk taking with regard to creative personality.

However, the main effect on curiosity was $F=3.57(p>.05)$, the main effect on open-mindedness was $F=2.94(p<.05)$, and the main effect on independence of judgment was $F=.23$ ( $p>.05$ ); thus, there was no statistically significant difference between the two groups with the pretest score controlled.

Meanwhile, curiosity $(p=.061)$ did not show a statistically significant difference at the significance level of $p<.05$ but showed a statistically significant difference at the level of $p<.10$, which indicates that this sub-factor is also affected by class activities including Jeong-jwa.

\section{Conclusions and Discussion}

It was found that the class activities including the Jeong-jwa activity based on the idea of Gyeong were effective in improving the creative personalities of the high school students. Among the sub-factors of creative personality, it was found that the Jeong-jwa activity highly affected task commitment, aesthetics, and risk taking.

In addition, it was found among the sub-factors that there were no statistically significant differences in curiosity and open-mindedness, but it is considered that the class activities including the Jeong-jwa activity had impacts to some extent. The impacts by sub-factor are as follows:

The conceptual definition of task commitment is the tendency to finish a task even when there are difficulties. The characteristics to measure with the test items were a tendency to devote oneself to a goal and concentrate on it for a long time, a tendency to not give up a task no matter how difficult it is, and thoroughness in what one wants to do. In a word, the characteristics can be described as the learners' 'immersion' in learning. If Gyeong is 'concentration' on tasks, and the Jeong-jwa activity is preparation for concentration of mind, a statistically significant and high test score for task commitment can be interpreted as a direct effect of the Jeong-jwa activity.

The impact of risk taking can be interpreted in the same line of discussion on task commitment. Risk taking means the tendency to risk the possibility of failure and do what one wants to do. The characteristic intended to be measured through the test items was the tendency to face new situations rather than safe and familiar situations, and take on the situation if it is what one wants to do despite the risk of failure. If the fear of failure is defined as an unnecessary distraction against concentration on what one wants to do, the Jeong-jwa activity can be interpreted as having the effect of reducing such distraction and focusing one's mind on what one wants to do. 
In terms of its conceptual definition, aesthetics is an interest in artistic activities and an outstanding sensitivity. The characteristics that we attempted to measure through the test items were attraction to mysterious and beautiful things, interest in artistic values and activities, and sensitivity in daily life. Sensitivity is an aesthetic tendency that can be displayed when emotions can be harmonized and controlled. Gyeong pursues the state of staying focused without embracing other thoughts (其心 收斂不容一物). If the idea of staying focused by forgetting distractions (主一無適) refers to ideas that are mainly exposed in consciousness, staying focused without embracing other thoughts includes subconscious or unconscious issues. If you have any stereotypes, biases, emotions, greed, lingering attachments, affection or baggage in your mind, you might make mistakes. In other words, even if you have prevented the distractions in your consciousness from impeding your concentration, something in your subconsciousness that you are unaware of should not prevent complete concentration [7]. This is not much different from the discussion [18] that the characteristics of aesthetics of Confucianism emphasize the function of the moral cultivation of artistic aesthetics. Therefore, it can be considered that Jeong-jwa had an effect of having a positive sensitivity; that is, artistic and moral sensitivity about what is going on around you by reducing the distractions in your mind that may spoil things with mind control and concentration.

Meanwhile, although curiosity did not have a statistically significant difference among the sub-factors of creative personality, it can be considered that the Jeongjwa activity had a significant impact by considering the level of significance at $p<$ .10. Curiosity is a tendency of wanting to learn about things through observation, and has an attribute of seeking to resolve curiosity about the issues or things around you using the 'why' question anytime, rather than just passing by the unseen objects or phenomena. This is considered to be relevant to the effect of the Jeong-jwa activity on improving the elaboration strategy and the assistance and resource use strategy in the self-control learning strategy. The learning reconstruction process, including establishing the causal and analogical relationships of the learned concepts, requires concentration on the part of the learners. This is because the strategy to use assistance and resources is essential to resolving the issues during the learning process.

Discussions on several issues took place during the research process, and recommendations for follow-up research are as follows:

First, some subjects failed to deeply focus on the Jeong-jwa activity, or considered it to be the same as taking a break. Although the teachers explained the meaning of the Jeong-jwa activity and emphasized its importance, the 5-minute Jeong-jwa activity at the beginning of the class after making a fuss during the 10minute break time was a bit too short for the students to concentrate on Gyeong. For this reason, it is necessary to carefully select the time to perform the Jeong-jwa activity, such as the morning meeting time or day-end meeting time.

Second, the application times of the Jeong-jwa activity were somewhat lacking. Since the Jeong-jwa activity was practiced only in the ethics class once a week, it was considered that other variables might have had impacts on the characteristics of the students. Of course, although the research was designed to minimize variables other than the Jeong-jwa activity, the Jeong-jwa activity may have more accurate effects when it is practiced at all times in daily life. For this reason, it is necessary to develop a program to continue to practice the Jeong-jwa activity, not only in the class but also in daily life, and plan research to verify the effects.

Third is the matter of the timing of the application of the Jeong-jwa activity. This research applied the Jeong-jwa activity beginning in the second semester, after the basic characteristics of the research subjects had already been fixed. It is considered necessary to apply the Jeong-jwa activity earlier, so that the activity can have the 
maximum impact on the characteristics of the research subjects. Of course, if the timing is too advanced, there is also the risk that the characteristics of the groups before applying the Jeong-jwa activity may be reflected in the statistical results. Therefore, it is necessary to have an in-depth discussion on the timing of the research.

Fourth, the measurement tool used to verify the effects of the Jeong-jwa activity should be considered. It is considered to be difficult to sufficiently sense the changes in the inner tendencies of individual students using only the test sheets in the form of a questionnaire. Of course, it is significant to digitize the overall changes of the research subject groups using the verified test tools in researching the effects of the Jeong-jwa activity. However, if the evaluations from the affective perspectives are done using the interviews and observations of the teachers and the statements of friends, it is expected to be possible to find effects that did not emerge from the statistical data.

Fifth, there should be precedent studies to conceptualize and interpret the idea of Gyeong and the Jeong-jwa activity in an educational manner. The students had only an abstract concept of the idea of Gyeong, and seemed to find it somewhat difficult to understand and learn the Jeong-jwa activity in detail. Modern pedagogy divides and conceptualizes academic capabilities or personalities into sub-factors and verifies their characteristics and effects. To diversely expand and verify the effects of Gyeong that have been discussed in the theory of study from a moral perspective, it is necessary to conceptualize and structuralize an idea of Gyeong that is tailored to the modern meaning, and to subdivide and conceptually organize the areas and characteristics of the idea. This research will aid in the development of an educational program for the students as research subjects to specifically understand and acquire the idea of Gyeong, and to more accurately verify the educational effects of Gyeong.

In this research, the Jeong-jwa activity did not have partial effects on the academic self-regulated academic capabilities and the sub-factors of creative personality, but did have sufficiently significant results in general. It is expected that more significant follow-up studies can be conducted based on the abovementioned issues and recommendations.

\section{References}

[1] C. Nanshim, "21st Schooling, what do we teach?", 2nd Anniversary Seminar Materials of Korea Institute for Curriculum and Evaluation (KICE). Research Material ORM 2000-1, Seoul, (2000).

[2] S.In-Sub and K. H.-Sook, "An Exploratory Study of the Establishment of Concept on Creativity", Journal of Educational Psychology, vol. 13, no. 3, (1999), pp. 97-117.

[3] H. Juhyun, "Development of Creative Personality Scale (CPS)", Journal of Educational Psychology, vol. 14, no. 2, (2000), pp. 187-210.

[4] H. Juhyun, "The study of validation of Creative Personality Scale (CPS) by age and development of creative personality", Journal of Educational Psychology, vol. 15, no. 3, (2001), pp. 323-351.

[5] K. Chungja, "The Relationship between Achievement goal and Creative Thinking of Secondary School Students", Journal of Yeolin Education, vol. 17, no. 3, (2007), pp. 1-20.

[6] P. Seongik and L. Kyounghoon, "The Relationships among motivation types of achievement goal, creative thinking ability, and creative personality of 4th grade students in elementary School", Journal of Educational Psychology, vol. 24, no. 1, (2010), pp. 137-158.

[7] Y. Yongnam, "Systematic Understanding of Zhu Xi's Gyeongsol", Journal of Ethics Education, vol. 35, (2014), pp. 315-330.

[8] K. CheolHo, “Mindfulness(敬), A Clue of Integrated Moral Education”, Educational Research, vol. 48, (2010), pp. 79-109.

[9] Classified Conversations of Master Chu (朱子語類), (1270), pp. 117-43.

[10] Classified Conversations of Master Chu (朱子語類 ), (1270), pp. 12-88.

[11] Classified Conversations of Master Chu (朱子語類), (1270), pp. 12-94.

[12] Teogye`s complete collection, vol. 28-37, 答李平叔. 
[13] Y. Hwang, “Toegyejip 28”, (1968)

[14] P. J.-Yong, "The Study on the Way of Learning Included in Toegye's Poems", The Study of Confucian Thought and Culture, vol. 56, (2014), pp. 253-290.

[15] Classified Conversations of Master Chu (朱子語類), vol. 12, pp. 217, (1270).

[16] L. Y.-Hee, "Hwal-in-shim-bang: Toegye' Body Study (MomGongBu) from the Mind", Yeomunseowon, Seoul, (2008).

[17] P. Seonghee, “Toegye's Confucianism and Counseling”, Hakjisa, Seoul, (2007).

[18] L. T.Hoo, "The History of Chinese Aesthetics", Daehan Printing \& Publishing Co., Seoul, (1992).

\section{Authors}

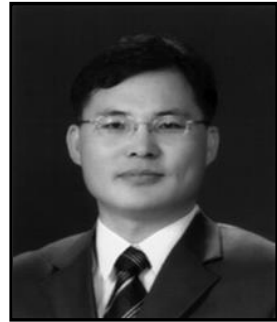

Seak-Zoon Roh, he is an Associate Professor of Education at Sungshin Women's University, Seoul, South Korea. He earned his $\mathrm{PhD}$ degree in Instructional Systems Technology from Indiana University Bloomington, USA. His research focuses on developing and implementing effective instructional design guidelines for distance education and high education, as well as Web accessibility.

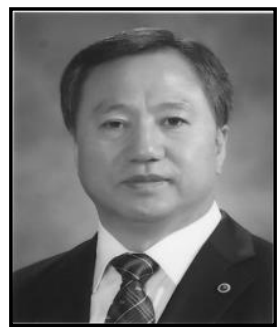

Yongnam Yun, he is a Professor of Ethics Education at Sungshin Women's University, Seoul, South Korea. He earned his PhD degree in Major of Eastern Philosophy from The Graduate School of Sungkynkwan University, Seoul. Korea. His major is NeoConfucianism and Korean philosophy. He is currently interested in applying eastern philosophy to everyday life.

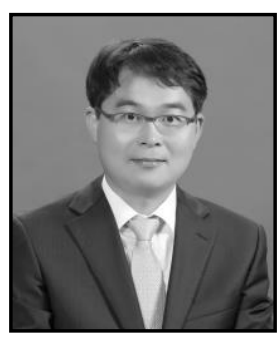

Jin-Sung Yang, he is a Teacher at Youngshin Girls' High School, Suwon, South Korea. He teaches Ethical Theory and Applied Ethics. He completed his doctoral course in the Graduate School of Korean Studes, Seongnam, South Korea. His research focuses on Chu Hsi's theory of kung-fu (工夫, self-cultivation). 
International Journal of $u-$ and e- Service, Science and Technology Vol.9, No. 6 (2016) 